This item was submitted to Loughborough's Research Repository by the author.

Items in Figshare are protected by copyright, with all rights reserved, unless otherwise indicated.

\title{
Rural young people and physical activity: understanding participation through social theory
}

PLEASE CITE THE PUBLISHED VERSION

PUBLISHER

(C) Wiley-Blackwell

\section{VERSION}

AM (Accepted Manuscript)

\section{LICENCE}

CC BY-NC-ND 4.0

\section{REPOSITORY RECORD}

Lee, Jessica, and Doune Macdonald. 2019. "Rural Young People and Physical Activity: Understanding Participation Through Social Theory”. figshare. https://hdl.handle.net/2134/5938. 
This item was submitted to Loughborough's Institutional Repository (https://dspace.lboro.ac.uk/) by the author and is made available under the following Creative Commons Licence conditions.

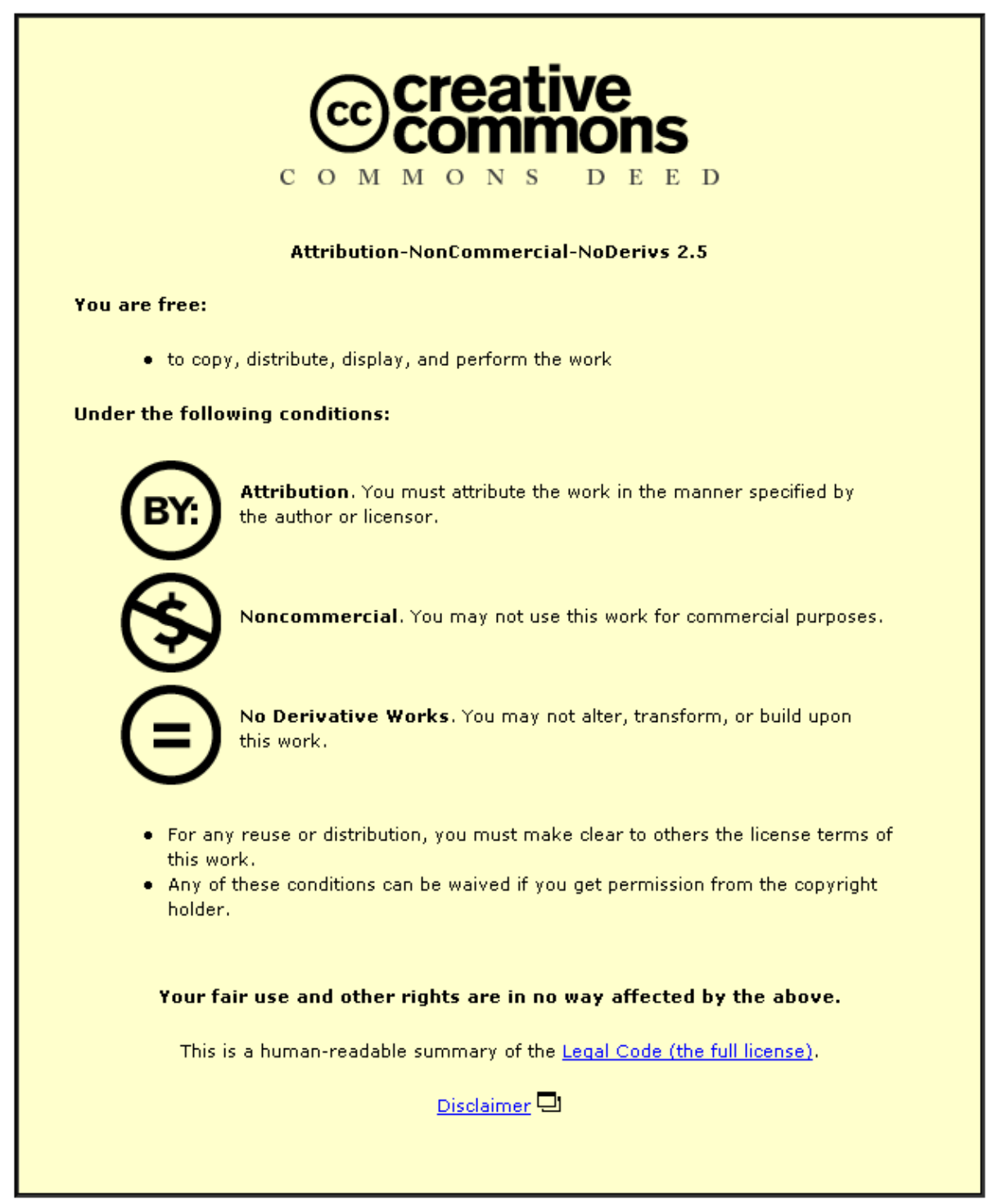

For the full text of this licence, please go to: http://creativecommons.org/licenses/by-nc-nd/2.5/ 
Rural young people and physical activity: Understanding participation through social theory

Jessica Lee

School of Sport and Exercise Sciences, Loughborough University, UK

Doune Macdonald

School of Human Movement Studies, The University of Queensland, Australia

Correspondence:

Dr Jessica Lee

School of Sport and Exercise Sciences

Loughborough University

Leicestershire

LE11 3TU

UK

Tel:+44 (0)1509 223275

Fax: +44 (0)1509 226301

E-mail: j.lee2@1boro.ac.uk

Paper published in Sociology of Health and Illness, 31 (3), 2009. 


\begin{abstract}
Studies from around the world point to the inadequate participation of young people in physical activity and sport, and the consequences of this on their health. However, very few interventions to increase the levels of physical activity amongst young people have been sustainable. The aim of this paper is to use Bourdieu's notions of the logic of practice along with habitus and capital to theorise young people's participation in physical activities to add to the wealth of empirical material. Data is drawn from a cohort of rural participants in an Australian longitudinal, qualitative research project with young people from diverse social, cultural and geographical backgrounds. It was found that traditional rural gender roles impact on young women's perceptions of legitimate physical activity options and practices. The role of the family in the reproduction of the social order which sustains gendered understandings of physical activity is also explored. This paper demonstrates how Bourdieu's theories can be applied to explain gender distinctions in health behaviours. It is proposed that building bridges between epidemiological and sociological understandings of participation in physical activities will lead to the generation of more equitable and sustainable physical activity and health promotion initiatives.
\end{abstract}

Keywords: Physical activity, rural young people, Bourdieu, health promotion 


\section{Rural young people and physical activity: Understanding participation through social theory}

Comparatively little is "known" about rural young people's participation in physical activities. Rural young people have been identified as participating in less sport and physical activities than their urban counterparts (Mummery, Schofield, Abt and Soper, 2000) as well as being just as likely to participate (Savage and Scott, 1998). This discrepancy may be due in no small part to the diversity of rural settings both within and between countries. Despite conflicting evidence, the health of rural young people has come to the attention of governments in Australia as they have identified rural areas as targets for health and physical activity promotion initiatives. The epidemiological data that underpin these policies and initiatives however, are problematic as they do not provide any means of understanding how young people themselves engage with discourses around health and make sense of their participation or non-participation in physical activity. As such, we propose that more extensive and theoretically rigorous research is needed in order for health promotion interventions to have an impact.

Studies of health that utilise social theory have proposed that individual health behaviours are reflective of wider socio-historical contexts within which people live their daily lives. As such, health practices such as diet and physical activity are learnt and embodied through the internalisation of the social surroundings (Warin, Turner, Moore, and Davies, 2008; S. Williams, 1995). In their study of women's views on obesity, Warin et al. (2008) found that meanings around food, diet, and eating were related to social class and life experiences, "that could not be explained or reduced to biological reasoning" (p. 8). From this perspective, popular public health discourses of individual responsibility and victim blaming which suggest that lifestyles are simply a matter of personal choice become particularly problematic (S. Williams, 1995). It has also been suggested that an epidemiological approach considers social structures such as race, class and gender as individualised inputs and, as such, the interplay of these factors from a historical perspective 
remains unexamined (G. Williams, 2003). Therefore a move beyond epidemiology is required to explore and theorise the social and structural dimensions of why individuals and groups behave the way they do (G. Williams, 2003).

Current approaches to physical activity promotion often fail to consider the impact of social structures on meanings given to physical activity and health which affect actions and "choices" around being physically active. Furthermore, Azzarito (in press) suggests that current top-down policies and interventions lead to standardisation and sameness in ideals of health and participation in physical activities and do not account for diversity in cultural approaches to health behaviours. This perhaps explains, in part, the limited success of interventions to increase physical activity at a population level. The use of qualitative research and social theory can help us understand "what is going on" in terms of the discrepancy in statistics and failing interventions.

Therefore, the purpose of this paper is to examine the complex interplay of cultural forces which shape rural young people's engagement with physical activity through the use of qualitative methods. Bourdieu's theoretical framework, based on social and cultural analysis is employed, as it allows for the flexibility required in the exploration of how rural young people engage in different ways with undeniable social and economic structures such as class, geographical location, family, and sex to shape the diverse patterns of engagements with physical activity. Bourdieu's consideration of structure and agency in his concepts of habitus, capital, and field are particularly relevant to the current research.

Bourdieu described the embodiment of social rules, values, and dispositions as the habitus (Bourdieu, 1977). The habitus, as an internalisation of the social world, shapes individual actions, thoughts and feelings based on a history of experience. Thus, Bourdieu (1984) labels the habitus as a "structured, structuring structure" (p. 170) as it is a result of internalising the social world 
(structured structure) which organises practices and the perception of practices (structuring structure). The social world can be thought of as constructed by fields characterised by struggles for power or dominant positions. Bourdieu acknowledges that many forms of power exist in social life and refers to all forms of power as capital (Laberge and Kay, 2002). The habitus, as an embodiment of social and cultural experiences, reflects a configuration of capital acting as a form of social currency and conferring power to those who possess the legitimised forms of capital within fields. Capital can take the form of economic assets, cultural competence in legitimised or dominant activities, and social resources linked to a social network (Bourdieu, 1986). Bourdieu considers the family as one of the major sites of the accumulation and transmission of capital and in this way the family plays a decisive role in the reproduction of the social order between generations (1996). Power within a field in the form of capital, especially economic and cultural, has the potential to mediate one's participation in a particular field such as sport and physical activity (Bourdieu, 1978). The intersection of two fields, sport and physical activity and rurality, and the associated legitimised forms of capital particularly associated with gender and social reproduction through the family, are examined in this paper.

Adherence to traditional gender roles in rural settings has attracted some academic attention (e.g. Campbell and Phillips, 1995; Davidson, 2001; Dempsey, 1992) and is of importance to the current study. Traditional gender roles are firmly embedded in rural communities as the activities most obviously linked to farm production and income are culturally understood to be men's activities, while women are recognised as helpers or supporters (Davidson, 2001). Studies of the rural gender order have revealed that this hegemonic masculinity extends into leisure sites like public bars and social occasions (Campbell and Phillips, 1995) and popular rural physical activities such as camp drafting and bull riding (Henry, 1998). As Gard (2001) puts it, “...sport, masculinity and country life are concepts which come together easily" (p. 20). 
Bourdieu did not initially identify gender as a classifying structure and it was only after criticisms and interpretations by feminist scholars that he reconsidered its importance. It is through Bourdieu's notion of embodied cultural capital (1986) that feminist scholars incorporate gender (Laberge, 1995; Lovell, 2000; McCall, 1992; Skeggs, 1997). Bourdieu (1986) describes embodied cultural capital as being "in the form of long-lasting dispositions of the mind and body" (p. 243) and identifies it as one of three forms of cultural capital. Bourdieu adds that the accumulation of embodied cultural capital implies "a labor of inculcation and assimilation" (1986, p. 243) which happens over time and through personal investment (perhaps subconsciously). Laberge (1995) associates this description of body and mind dispositions with gendered dispositions as they are acquired over time through the process of socialisation. As such, she proposes, "gendered dispositions appear to be thoroughly akin to the embodied state of cultural capital" (Laberge, 1995, p. 138).

Whilst the above explanations proposed by feminist researchers are simply interpretations of Bourdieu's work, Bourdieu himself encouraged a generative reading of his theoretical perspective. By this he implied that researchers should apply the model in their own "particular place of the possible" and construct their specific social space and symbolic space, to define the basic principles of objective differentiation (Bourdieu, 1998, p. 13). In relation to capital Bourdieu states, "Capital [is an] energy which only exists and only produces its effects in the field in which it is produced and reproduced, each of the properties attached to class is given its value and efficacy by the specific laws of each field" (Bourdieu, 1984, p. 113). This statement points to the situatedness intended by Bourdieu in his concept of capital and reinforces his invitation for a located application of his theoretical framework. As such, based on the interpretations of feminist scholars and Bourdieu's own intention for the generative use of his theories, gender will be explored as a strong contributor to patterns of distinction in the rural sport and physical activity field. The use of a theoretical framework to explain the rural young people's participation in physical activity will contribute 
added meaning to the literature on participation patterns and statistics. The following section offers a brief overview of the informing methodology and subsequent method of the current research.

\section{Research method}

The data presented in this paper are part of a larger, longitudinal study, the Life Activity Project (LAP) (see Authors, 2004; 2006). The purpose of the LAP was to examine the place and meaning of physical activity in the context of young people's lives and in doing so, to investigate some of the taken for granted assumptions about young people's participation in physical activity and the relationship between physical activity and health that underpin practices in physical education and in public health promotion. For the larger project, interview data were collected over a period of seven years (1999-2006) with a cohort of young people $(n=97)$ from various geographical and social locations in three states in eastern Australia. One-off interviews with a sample of parents and school Physical Education teachers were also conducted. The interview data collected over three years from one sub-group of Australian rural young people and their parents are the focus of this paper. Rural young people from two states were purposely sampled through schools for the LAP, however there were substantial differences in experiences of physical activity between the rural cohorts from different states and are therefore not combined for analysis. The cohort of focus in this paper were more remote, geographically spread and initial response rate to participation was low, resulting in a smaller sample (see following section). The research method for the larger study was informed by a poststructuralist theoretical perspective which, as Sparkes (1992) proposes, will have an impact upon how the social researcher views the world and thus, her modes of enquiry.

The methodology employed borrows from the ethnographic tradition which is consistent with the poststructural theoretical perspective and is appropriate to address the main research questions with 
its principle that behaviour is contextual and understanding it requires the knowledge of why the certain behaviour takes place and under what circumstances. Ethnography is also a reflexive process as it is implicit that the researcher is a part of the world that she studies and is affected by it (Boyle, 1994). The researcher (first author) identified with the standpoint of the outsider within (Hill Collins, 1991) as through repeated interaction with participants in participants' own familiar settings, her insider/outsider identity was renegotiated throughout the course of the research project. Importantly, the outsider within is able to retain their "original commitments and values but makes use of them to understand a new community into which [they are] also being socialized" (Acker, 2000, p. 10).The poststructuralist theoretical perspective and ethnographic methodology informed the specific research methods that are described below.

\section{Participants and settings}

The participants were a cohort of rural young people and their parents. The young people ranged in age from 11 to 15 years old at the time of recruitment. This age range allowed for the inclusion of young people who were in their final year of primary school, first year of secondary school and final year of compulsory schooling. Participants lived in various rural locations in Queensland, Australia as they were recruited from a government secondary school in a rural town and a school of distance education.

Greenvalley High, the government secondary school, was located in a small town 100 kilometres from a major city. While physical distance was not great, the community, particularly the young people, was somewhat isolated given the lack of local services and access to public transport between nearby towns and larger centres. Some of the young people attending Greenvalley High lived on residential blocks in the town while others lived on properties up to 30 kilometres away from the school. The school of distance education caters for students who cannot, for various reasons, attend regular schools and as such, has a high proportion of students who live in remote 
rural locations. Distance education entails students receiving hard copies of learning materials and guidance on daily work plans from teachers. Personal communication is usually via telephone, sometimes email (depending on access) and audio-tapes can be used for assessment. The young people studying via distance education lived on farming properties in four different rural locations up to 600 kilometres from the state capital and between 20 and 60 kilometres from the nearest town. The participants and locations reflect the diversity evident among rural young people and included young people who had varying levels and types of participation in physical activities. This paper draws on data from a sample of 11 participants including six girls and five boys. See Table 1 for details of participants' ages, schools, and locations.

\section{INSERT TABLE 1 ABOUT HERE}

\section{Data collection and analysis}

Data used in this study were collected through a series of semi-structured interviews over a period of three years. Where possible, interviews were held face-to-face between the researcher and the participant, however due to vast distances, some interviews were held over the phone, via audio tape, or email. When interviews were held face-to-face, participants chose a venue which best suited them. This included their own homes, school, workplace, or local facilities such as cafes. While sometimes more convenient and cost effective, Fontana and Frey (2003) suggest that interviews via telephone and email may yield more cryptic and less in depth responses. In the current project, no difference was noted between data gathered via telephone interview versus faceto-face interactions. As proposed by Babbie (2001), it was sometimes even easier to approach more sensitive areas over the phone as they "don't have to look you in the eye” (p. 236). Interviews conducted via audio tape and email however, were more like structured interviews as the medium did not allow for further probing on interesting topics and therefore had to be followed up with telephone or face-to-face interviews. As the audiotape interviews yielded inferior data on their own, 
this medium was only used for one early round of interviews and email was used only for parent interviews.

Each young person participated in two to four interviews each year over three years focusing on topics including health and fitness, bodies and sport in the media, geographical location and local communities, and past and present participation in physical activities. Parent interviews discussed the parents' own meanings of health and fitness and their involvement in their children's participation in physical activities.

Interviews were transcribed verbatim and coded into themes using the QSR NVivo 2 qualitative research software package. In keeping with a poststructural theoretical perspective, an ideographic approach to the data analysis was taken which is not judgemental but rather allows the subject to reveal its nature and characteristics during the process of investigation (Sparkes, 1992). Interview responses were coded into themes as they emerged (that is, no pre-determined categories were used) and then further analysed to refine groupings and categories and to search for recurrences of certain words or text within sets of documents. Ethnographic analysis involves the search for patterns in data and for ideas that help explain the existence of those patterns (Boyle, 1994). Patterns of responses coded into the themes are reported in the following section. Data in the form of quotes from interviews are included alongside an analysis using Bourdieu's theoretical framework to go beyond description into explanation and understanding.

\section{Towards an understanding of rural young people's participation in physical activities}

Two major data trends in rural young people's participation in physical activities were observed. The first trend emerged as gender differences in the young people's physical activity participation 
patterns. In particular, the gender differences were played out in the differentiation between the young women and young men in participation in sport and also the ways in which they perceived physical labour. The second trend was the importance of family both in terms of encouragement and support but also as a form of social interaction. These two trends will be discussed in terms of how habitus and capital intersect with the social setting to shape certain actions.

\section{Gendered perceptions and patterns of participation}

The young women's participation in physical activities included for some, sport and physical labour, however for most, it was restricted to physical recreation in or around the home. Lisa, a participant in equestrian and highland dancing, was the only young woman in the cohort who was involved in sports (or organised physical activities) for the duration of the study. Typical examples of physical recreation among the young women included sports played with siblings or friends (tennis, swimming), individual exercise routines (sit-ups, boxing bag), active play (trampoline, 'totem' tennis), and walking. Lisa and Sally also participated in physical labour, Sally as part of her paid work on a turf farm, and Lisa as part of the up-keep and training of a stable of horses.

Int.: What sort of physical activity are you doing at the moment outside of school?

Tammy: Not a lot. I walk my dog a bit... I'm doing training at home because I want to start kickboxing, so I'm trying to get fit for that... we've got the kick-bag at home, so I mostly use that and just push-ups and sit-ups and things like that.

While most of the young women did participate in recreational physical activities and physical labour, they did not perceive these forms of physical activity as legitimate because of the dominance of sport and exercise discourses. For example, although Jacinta believed she was physically inactive, she mentioned as a fourteen year old at the start of the study, that she jumped on the trampoline, walked, and danced in her leisure time. 
Int.: What physical activity are you doing at the moment?

Jacinta: I don't think any, any more. I'm sort of like finished and I'm just doing things at home... I go out and talk to my sister who's usually outside on the trampoline. We just start talking and then we go down the road, we go for a walk down the road because there's nothing else to do... [I also] Dance to music. I turn on 'Rage' and I'm just standing there dancing.

It is notable that in both these examples, the young women expressed that they participated in very little or no physical activity before listing a number of recreational physical activities.

The young women involved in physical labour discussed these activities in terms of chores or responsibilities rather than physical activity. Lisa captured this distinction between work and physical activity (or exercise) by saying, "It's not really a physical activity because I'm not doing it to get fit". Sally described herself as inactive and felt that she needed to "exercise more, do a lot of sports", although at the time she was responsible for grooming horses and working at a turf farm before school.

Int.: Where do you normally work?

Sally: At a turf farm... I roll turf... for about an hour and a half, two hours every morning and then I go to school.

I: So that involves pushing the turf along and running along behind it?

S: And picking it up and loading it on the truck.

As these young women identified themselves as physically inactive despite participating in physical forms of labour and recreation, quantitative-based studies relying on self report to measure physical 
activity participation would not capture these legitimate forms of physical activity. This finding supports Sleap and Wormald's (2001) research which suggests that girls are physically active in the form of chores and in less formal or traditional activities. Indeed, this finding may clarify the role of meanings of physical activity to explain the differences between boys' and girls' participation observed in the literature.

Given the young women's talk about "what counts" as physical activity and their somewhat restricted participation patterns (particularly in comparison to the young men), it is inferred that their conceptions of physical activity were not consistent with the rural feminine discourse. As such they perceived a lack of legitimised feminine physical activity options. When asked about the physical activity options in their communities, the young women often mentioned activities and sports that they could not access like cricket and football (rugby league) clubs, and facilities like a skate park that were dominated by male "skatey bums" (Tammy).

Sharon: [I]t's based around all boys' sports and stuff like that, they should put more like female sports and stuff.

Int.: So what, what sports would you put in?

S: Oh netball and stuff like that, just more based at females...

When asked what she thought would increase young people's participation in physical activities Cassie said,

I suppose by, I don't know, just including a lot more physical activities and different sorts of sports. Not just your football, basketball, cricket that sort of thing. Like do a lot of other things. Like, I know a lot of people who do horse riding and equestrian and all that sort of stuff. Pretty much just different sorts of sports. 
Lisa, the only young woman in the cohort to be involved in a sport, participated in equestrian events, particularly dressage, which while it does include male participants, remains consistent with feminine discourses of grace, beauty, and elegance.

The young men in the cohort were involved in more sports, as there were more opportunities and facilities for (so called) boys' sports. Their activities included cricket, swimming, volleyball, golf, touch football, State Emergency Services and army training, and pistol shooting. Of the young men who were not involved in organised physical activities, all were regularly involved in physical labour. In contrast to the young women, being involved in farming work constituted legitimate physical activity for the young men. Tyrone and Will were not involved in any sport, but were keen to demonstrate that they were still physically active in their farm chores such as wood chopping, sheep and cattle mustering, and sheering.

Will: Well what kinds of physical activity have [I] been involved in outside of school? Well working around the property for one. Dad keeps us very busy, like [with a] property to run with shearing, branding... and that keeps us pretty fit.

Indeed, Will gauged his physical fitness level according to the types of farm chores that he could accomplish.

Will: ... I get a fair bit of physical activity... I went up to a dry dam and there was three sheep stuck in there, in the mud. The mud would have sucked against them right, so it's really tough work, you've got to be really fit to pull them out... basically by myself and then we lifted them into the trailer and take them back here and wash the mud off them and feed and water them. So you know, a fair bit of fitness is needed to do things like that. 
Physical labour also appeared in some of the rural young men's descriptions of their leisure time.

Tyrone rode his push-bike around his property and incorporated his recreation time with his chores.

Int.: So what sort of stuff do you normally do at home, when you're not doing your school work or your chores?

Tyrone: [Push-] Bike riding, straight away. If Mum wants me to go and check the trough over there and make sure it's not overflowing or anything and I'll be back about an hour later, just checking the trough and I'll go up the road and up the other side there, coming down the other side there's good [tracks]. I think it's eight kilometres or seven.

For this cohort of young people, gendered power appeared to be most dominant in the social order of the sport and physical activity field within the rural setting. Their habitus are shaped by the internalising of this social setting. As the habitus is a set of dispositions that motivate action in the particular field, the rural young people's apparent choices about participation in physical activities reproduced the gendered order of the rural social setting. Bourdieu explains this relationship between the field and habitus as follows, "the relationship of immediate adherence that is established in practice between a habitus and the field to which it is attuned, the pre-verbal taking for granted of the world that flows from practical sense" (Bourdieu, 1990a, p. 68). Both the young men and the young women appeared to adhere to the gendered social order (doxa) which placed the young women in a subordinate position or subjected to symbolic violence in terms of legitimised activities and availability of facilities. The young men on the other hand, held the dominant power position and almost expected to be involved in sport and physical labour as a way of life. Bourdieu would suggest this doxic attitude or adherence to the order of the field means that the gendered social order is misrecognised allowing for the operation of symbolic violence. Although not explicitly attributing their non-participation to gender discrimination, the young women did mention 
lack of access to the sports that they would prefer to do such as netball, tennis, and equestrian. These sports are widely accepted as suitable for women as opposed to the ones that they listed as being available in their local areas (e.g. cricket, rugby league).

This model is not to be interpreted as overly deterministic. While acknowledging the gendered power structure of rural settings, Hunter and Riney-Kehrberg (2002) highlight the debates about the agency of rural children in constructing their own lives. Evans's (2002) use of the concept bounded agency is particularly useful in this situation as it sees agency as a "socially situated process, shaped by the experiences of the past, the chances present in the current moment and the perceptions of possible futures" (p. 262). As such, while young people are indeed displaying a sense of agency, "there are a number of boundaries or barriers that circumscribe and sometimes prevent the expression of agency" (Evans, 2002, p. 262). In Bourdieu's terminology bounded agency is demonstrated in the following quote, "Agents shape their aspirations according to concrete indices of the accessible and inaccessible and, of what is and is not for us" (Bourdieu, 1990a, p. 64, emphasis added). It is important to point out that this is not a conscious effort on behalf of the individual to "adjust their aspirations to an exact evaluation of their chances of success" (Bourdieu, 1990a, p. 54), rather that the habitus, "without violence, art or argument tends to exclude all 'extravagances' ('not for the likes of us'), that is, all the behaviours that would be negatively sanctioned because they are incompatible with the objective conditions" (1990a, p. 56, emphasis added).

The case of Lisa being the only female to participate in a sport demonstrates her possession of the necessary social capital (access to equestrian clubs and coaches) and cultural and economic capital (knowledge of horse training and grooming methods, possession of land and equipment for horse riding), which afforded her the agency to participate in the sporting activity of equestrian. As noted earlier however, Lisa's access was available to an activity that is considered appropriate and 
legitimate for female participants. Rather than being structurally forced into certain actions, Lisa chose a sport that was consistent with her habitus. Bourdieu would term this occurrence as the logic of practice (1990b). While Lisa differed from the other young women, her personal trajectory still conformed to the gendered social order of the sport and physical activity field in the rural setting.

McNay (2000), drawing upon the work of Bourdieu and Butler, describes this situation as gender performativity. That is, the young people's reproduction of gender "does not refer to a voluntarist process of performance so much as a 'forced reiteration of norms' in the sense of a compulsory and constraining heterosexuality that impels and sustains gender identity" (p. 33-34). The gendered nature of the rural young people's participation in physical activities arises from the habitus and the deeply instilled social order and "every performance" both reproduces the gender norms of the field and reinscribes them upon the body. This performance of gender was not only evident in the young people's participation choices but also the way they understood and spoke about sports and physical activities. For example it was evident when Will spoke of some physical farm chores as "sort of rough, it's a boy thing”, and Sharon's comments about local facilities, “...based around all boys' stuff... they should put more like female sports and stuff'. This is not to say that the rural young women condoned or "authorised" the dominant position of the young men in reproducing gender "norms" (Skeggs, 2004, pp. 25-26). Rather than being a pre-reflexive misrecognition as Bourdieu would suggest (1990a), Skeggs (2004) proposes that women may willingly perform femininity to their advantage whilst holding discontent for traditional male power. It can be explained that the young women in the observed rural settings, while perhaps not authorising the gender structure, will enact legitimised feminine dispositions in order to gain cultural capital.

The interview quotes presented in this section represent a range from across the span of the three year project demonstrating the consistency of the gendered perceptions of physical activities. Actual participation patterns among the distance education participants also remained stable throughout the 
study perhaps due to the consistency of their circumstances as all remained at home with their families while they continued their high school education. Among the Greenvalley participants however, some changes in participation patterns were noted across time particularly as most either completed or left school during the course of the study. The Greenvalley young men continued to be physically active either in active occupations (e.g. army) or continued participating in sports, albeit with limited time due to work and/or study commitments.

Brett: ...I got a job at a propagating nursery and basically there up until about May, then started organising a [college] course and started off that at July.

Int.: Do you fit [in] any more training [for competitive shooting] now?

B: Not really, because I've sort of got to travel any where to be able to shoot. So unless Dad might be going near club, or my grandad might be... usually I don't get any more in... Usually if I did any practice for shooting it would be on Saturday, but I usually just turned up for the shoots on Sunday morning, shot for the day then went home.

For the Greenvalley young women, the gendered social world that shaped their habitus (internalisation of the social world) as young women continued to constrain their opportunities for physical activity post-school. For these young women, demanding family responsibilities such as caring for grandparents and siblings, in addition to full-time work, took priority such that physical activity became almost non-existent.

Int.: So what are your hours like these days [at the childcare centre]?

C: Yeah, they're still long, and they're still all over the place... The day I graduated [from high school] I came here [to stay at my grandmother's house]. My grandmother was feeling off colour and had to have a big operation.

I: So you came down to look after her? 
C: Yeah.... I don't really get a chance to do anything else now 'cause at work I'm the manager which means I cook and prepare the food for over a hundred and something children each day, I'm the only one in the kitchen...

It is interesting to note the durability of the habitus and the performance of gender appropriate activities across life transitions. The reproduction of physical activity perceptions and practices particularly through the family are discussed in the following section.

\section{The family and reproduction of physical activity perceptions and practices}

The habitus is not only a "structured structure" that is shaped by external social conditions; it is also a "structuring structure" (Bourdieu, 1990a, p. 53). As a structuring structure the practices motivated by the habitus reproduce the social order of the field and the social setting. This is where the role of the family becomes important. The data demonstrated that those young people who played sport or organised physical activities relied heavily on family support.

Lisa: Mum was very supportive in everything... I got involved with riding because Mum had horses and she was competing and judging... from the start of this year we just dance here at home, in our tiny little lounge room (laughing)... Mum teaches the dancing... six people, including me and my sister.

Mother: I drive them everywhere, I make them lunches if they're swimming and they've got to go to somewhere after ... there was one stage where we were picking him [Brandon] up from swimming, he had half an hour to have something to eat and we'd drop him off at [touch] football and he wouldn't get home until Monday night about eight o'clock... on Wednesday afternoons if they go to another school because we've got a Tarago [van] kind of thing we can just about get the whole team in, so we can take the whole team in one go. 
Indeed, for a number of the participants, their weekly attendance at sporting clubs was considered a time for family connectedness, both with each other and with other families.

Mother: Well I'm quite involved in club cricket. I usually score and help [my husband] set up things. So pretty much the whole family is involved...

Mother: [W]ith Friday night is a thing where we go to swimming club... and [my husband] helps with the barbecue...

Furthermore, of the parents interviewed, social skills appeared predominantly as a desired attribute that their children gained through participation in sport.

Mother: ...every minute they are involved, I am there... Lisa, especially, intends to go as far as is possible [in dressage]. Therefore, its [sic] my job to support her all the way, for as long as it takes.

Int.: What skills/characteristics do you think your children are obtaining by being involved in physical activities?

Mother: EVERYTHING!! The ability to manage time, to think logically about how to attain a certain goal, to get along with other competitors, to handle success and defeat... to be focused and determined, to be easy on yourself or hard on yourself when you need to be, to go looking for expert help, to develop networking skills, and on and on. (Yes, I guess being "fit" in its commonest interpretation fits in there somewhere as well.) (Interview conducted via email. Emphasis in original.) 
Mother: Since they started cricket a few years ago I've really seen them grow socially which is one great reason why they do it.

This finding supports previous research conducted with rural Australian families reporting that parents were willing to make financial and time sacrifices in order for their children to participate in sports due to the "social involvement with other children that sporting activities provide" (Rossi and Wright, 2002, p. 6). The importance of the family in physical activity participation can be seen as a form of social capital where parents consider organised activities as valuable for their children's social development and families tended to be involved in activities together.

It was also observed that the rural young people tended to "choose" sports that their parents had participated in or encouraged them to do. Many of the young men participated in sports that were played by their fathers who continued to occupy strong supporting roles and Lisa participated in equestrian and dancing with the enduring support of her mother who was also involved in both of these activities in her own right as a participant and teacher (see earlier quote).

Brett: I look up to my dad 'cause he's ranked seventh in the world for pistol shooting and yeah, I'd like to be there one day... probably my grandad as well 'cause he's a shotgun shooter.

Luke: $[\mathrm{T}]$ he people that encouraged me probably were my father who encouraged cricket because he was interested and also my grandfather, his father, was also interested. So I became interested in cricket.

Tyrone: I'm hoping to get back into playing cricket around here. Hoping to, I might be able to con Dad into playing a bit of B grade with me again, but he used to play A grade... 
The influence of parents and grandparents serves to reproduce the social order. In this way the family itself is a "structured, structuring structure" which creates a circularity of reproduction of objective social categories where capital is accumulated and transmitted between generations (Bourdieu, 1996, p. 21).

When participants lacked the social, cultural and economic capital needed to participate in physical activities, their non-participation was explained as a natural expression of taste. Cassie reported that sport was not regarded as very important in her family, "I'm not really that interested in sports... in our house it's kind of a forbidden thing". A gendered understanding of physical activity was evident in Cassie's interviews, for example when she complained of the lack of feminine physical activity options such as equestrian as opposed to the traditional masculine sports available in the nearby town. However, while Cassie's non-participation in, even rejection of, all physical activities was consistent with the gender order, her case provides an example of how the family's lack of economic and social capital can constrain physical activity opportunities. Cassie's family’s economic capital was very low as her parents received their sole income from a government disability pension. They lived about 25 kilometres from Greenvalley and were virtually isolated from family and friends as they could not financially afford the costs of regular travel into town or the regional centre where Cassie's maternal grandmother lived. Therefore their lack of economic capital also restricted the family's access to social capital. Cassie's family's "dislike" of sport as an expression of taste stemmed from distance and cost due to their lack of economic and social capital. Therefore her choice not to participate in physical activities was indeed due to her family's dislike of it as she explained, which was a result of a "taste for necessity" (Bourdieu, 1986, p. 372) arising from their social circumstances. 


\section{Conclusion}

The aim of this paper was to explore and theorise the patterns of participation in physical activity among a cohort of rural young people. The data presented demonstrates the role of both gender structures and the family in distinguishing participation patterns in sport, physical labour, and physical recreation. An important contribution of this paper is its demonstration of how gender can be used as a classifying structure in Bourdieu's theoretical framework alongside the major tenets of poststructuralism to explain the reported participation patterns.

In demonstrating the ways in which perceptions of, and participation in, physical activity are enmeshed in participants' taken-for-granted everyday practices, findings in this study concur with Warin et al.'s (2008), that the universality of health promotion messages are problematic. As actions and indeed meanings of actions reflect local, social contexts, the "gendered and classed habitus is at odds with current health-promotion policies or practices" as they "do not take account of local and relational worlds" (Warin et al., 2008, p. 3). While some initiatives are targeted specifically at certain populations we argue that the lack of attention to gendered and classed meanings attached to health behaviours is highly problematic for the uptake of health promotion initiatives and may limit the success of such programmes. The notion of gender performativity linked to bounded agency is important to consider as it was demonstrated that the rural young women, in particular, were unlikely to participate in activities that contradicted what was acceptable according to their gendered habitus. A sociocultural understanding of rural young people's engagement in physical activities can contribute to a more holistic and successful approach to policy development in the area of rural young people's health and participation in physical activity. While gender differences and family influences on young people's participation in physical activities are often reported in quantitative studies, this paper goes beyond participation statistics to try to understand the nature of the social worlds that produce gendered practices. 
It is acknowledged that the current study reports data from a very small cohort of rural young people. By providing careful descriptions of the social conditions, settings, and people being, other researchers have the information necessary to assess the typicality of a situation, to identify appropriate comparison groups and translation issues, and thereby to meet the requirements of rigor, and for want of a better term, generalisability, in the context of ethnographic research (Eisenhart and Howe, 1992). Furthermore, it must be recognised that ethnographic research with small samples allows for an in-depth and contextualised exploration of physical activity within the young people's lives, which is not afforded with traditional quantitative methods. The longitudinal data and consistency of the trends over time is a strength, demonstrating the deeply ingrained social structures, adherence to dominant discourses, and gender performativity in physical activity participation patterns. Future research of this kind on a larger scale is therefore justified.

The current study provides insight to what may contribute to the reported discrepancy between boys and girls in rates of participation in physical activities. The way that the young women conceptualised "what counts" as physical activity brings into question the accuracy of self-report measures of participation rates. Physical activity as sport and exercise was the dominant discourse which rendered most of the rural young women to classify themselves as physically inactive, despite participating in varied forms of recreational physical activities and physical labour. It seems that while in the academic and professional worlds, definitions of health enhancing physical activities are broadening, the young women reproduced narrow and gendered views of legitimate physical activities. In highlighting this issue with measurement, interpretation of participation statistics must also be assessed critically particularly when they portray young women as problematic and "at risk" due to their lower participation rates. Given the findings of this study, it is pertinent that future research continues to address participation in physical activity from a 
qualitative perspective and furthermore, that research of this kind is considered in the generation of sustainable health policies and initiatives. 


\section{References}

Acker, S. (2000) In/out/side: Positioning the researcher in feminist qualitative research, Resources for Feminist Research, 28, 1, 189-210.

Azzarito, L. (in press) The rise of corporate curriculum: Fatness, fitness, and whiteness. In Wright, J. and Harwood, V. (eds) Bio-pedagogies: Schooling, youth and the body in the 'obesity epidemic'. London: Routledge.

Babbie, E. (2001) The practice of social research. Belmont, CA: Wadsworth Thomson Learning.

Bourdieu, P. (1998) Practical reason: On the theory of action. California: Stanford University Press.

Bourdieu, P. (1996) On the family as a realized category, Theory, culture and society, 13, 3, 19-26.

Bourdieu, P. (1990a) The logic of practice. Stanford, CA: Stanford University Press.

Bourdieu, P. (1990b) In other words: Essays towards a reflexive sociology. Stanford, California: Stanford University Press.

Bourdieu, P. (1986) The forms of capital. In Richardson, J. G. (ed.) Handbook of theory and research for the sociology of education. New York Greenwood Press: New York.

Bourdieu, P. (1984) Distinction: A social critique of the judgement of taste. Cambridge, Massachusetts: Harvard University Press.

Bourdieu, P. (1978) Sport and social class, Social Science Information, 17, 6, 819-840.

Bourdieu, P. (1977) Outline of a theory of practice. Cambridge: Cambridge University Press.

Boyle, J.S. (1994) Styles of ethnography. In Morse, J. M. (ed.) Critical issues in qualitative research methods. Thousand Oaks, CA: Sage.

Campbell, H. and Phillips, E. (1995) Masculine hegemony and leisure sites in rural New Zealand and Australia. In Share, P. (ed.) Communication and culture in rural areas. Wagga Wagga, Australia: Centre for Rural Social Research, Charles Sturt University. 
Davidson, A.P. (2001) Farming women and the masculinisation of farming practices. In Lockie, S. and Bourke, L. (eds) Rurality bites. Annandale, NSW: Pluto Press.

Dempsey, K. (1992) A man's town: Inequality between women and men in rural Australia. New York: Oxford University Press.

Eisenhart, M.A. and Howe, K.R. (1992) Validity in educational research. In LeCompte, M. D., Millroy, W. L. and Preissle, J. (eds) The handbook of qualitative research in education. San Diego, CA: Academic Press.

Evans, K. (2002) Taking control of their lives? Agency in young adult transitions in England and the New Germany, Journal of Youth Studies, 5, 3, 245-269.

Fontana, A. and Frey, J.H. (2003) The interview: From structured questions to negotiated text. In Denzin, N.K. and Lincoln, Y.S. (eds) Collecting and interpreting qualitative materials. Thousand Oaks, CA: Sage.

Gard, M. (2001) Sport, physical education and country towns: diverse enough?, Education in Rural Australia, 11, 2, 19-26.

Henry, J. (1998) Bullriding into manhood. In Hickey, C. Fitzclarence, L. and Matthews, R. (eds) Where the boys are: Masculinity, sport and education. Geelong, Victoria: Deakin Centre for Education and Change.

Hill Collins, P. (1991) Learning from the outsider within: The sociological significance of Black feminist thought. In Fanow, M. M. and Cook, J. A. (eds) Beyond methodology: Feminist scholarship as lived research. Bloomington: University Press.

Hunter, K. and Riney-Kehrberg, P. (2002) Rural daughters in Australia, New Zealand and the United States: an historical perspective, Journal of Rural Studies, 18, 135-143.

Laberge, S. (1995) Toward an integration of gender into Bourdieu's concept of cultural capital, Sociology of Sport Journal, 12, 132-146.

Laberge, S. and Kay, J. (2002) Pierre Bourdieu's sociocultural theory and sport practice. In Maguire, J. and Young, K. (eds) Theory, sport and society. Oxford: JAI. 
Lovell, T. (2000) Thinking feminism with and against Bourdieu, Feminist Theory. 1, 1, 11-32.

McCall, L. (1992) Does gender fit? Bourdieu, feminism, and conceptions of social order, Theory and Society, 21, 837-867.

McNay, L. (2000) Gender and agency: Reconfiguring the subject in feminist and social theory. Malden, MA: Blackwell.

Mummery, W.K., Schofield, G.M., Abt, G. and Soper, L. (2000) Correlates of adolescent physical activity in regional Australia: Results from the Central Queensland Adolescent Physical Activity and Nutrition Study, AIESEP World Sport Science Congress Proceedings. Rockhampton, Australia: Central Queensland University.

Rossi, T. and Wright, J. (2002) Children's physical activity, health and physical education in isolated rural contexts: The views of parent educators in Queensland, Education in Rural Australia,12, 1, 2-7.

Savage, M.P. and Scott, L.B. (1998) Physical activity and rural middle school adolescents, Journal of Youth and Adolescence, 27, 2, 245-253.

Skeggs, B. (1997) Formations of class and gender. London: Sage.

Skeggs, B. (2004). Context and background: Pierre Bourdieu's analysis of class, gender and sexuality. In Adkins, L. and Skeggs, B. (eds) Feminism after Bourdieu. Oxford: Blackwell Publishing.

Sleap, M. and Wormwald, H. (2001) Perceptions of physical activity among young women aged 16 and 17 years, European Journal of Physical Education, 6, 26-37.

Sparkes, A.C. (1992) The paradigms debate: An extended review and a celebration of difference. In Sparkes, A. C. (ed.) Research in Physical Education and Sport: Exploring alternative visions. London: The Falmer Press.

Warin, M., Turner, K., Moore, V., and Davies, M. (2008) Bodies, mothers and identities: rethinking obesity and the BMI, Sociology of Health and Illness, 30, 1, http://www.blackwellsynergy.com/toc/shil/0/0 
Williams, S. J. (1995) Theorising class, health and lifestyles: can Bourdieu help us? Sociology of Health and Illness, 17, 5, 577-604.

Williams, G. H. (2003) The determinants of health: structure, context and agency, Sociology of Health and Illness, 25, 131-154. 
Table 1: List of participants ${ }^{*}$, their schools, ages, and locations.

\begin{tabular}{|c|c|c|}
\hline Participant & Age at recruitment & Location \\
\hline \multicolumn{3}{|c|}{ Greenvalley High Participants } \\
\hline Cassie & 15 & $\begin{array}{l}\text { Residential housing estate, } 25 \mathrm{~km} \text { from } \\
\text { Greenvalley }\end{array}$ \\
\hline Sharon & 15 & Residential block in Greenvalley \\
\hline Jacinta & 13 & $\begin{array}{l}\text { Residential block } 15 \mathrm{~km} \text { from } \\
\text { Greenvalley }\end{array}$ \\
\hline Tammy & 13 & $\begin{array}{l}\text { Small property } 10 \mathrm{~km} \text { from } \\
\text { Greenvalley }\end{array}$ \\
\hline Sally & 13 & $\begin{array}{l}\text { Small property } 20 \mathrm{~km} \text { from } \\
\text { Greenvalley }\end{array}$ \\
\hline Brett & 15 & $\begin{array}{l}\text { Small property } 12 \mathrm{~km} \text { from } \\
\text { Greenvalley }\end{array}$ \\
\hline Brandon & 13 & $\begin{array}{l}\text { Crop farming property (145ha) on the } \\
\text { outskirts of Greenvalley }\end{array}$ \\
\hline
\end{tabular}

\begin{tabular}{|c|c|c|}
\hline \multicolumn{3}{|c|}{ Distance Education Participants } \\
\hline Lisa & 12 & $\begin{array}{l}\text { Small property in a small town, } \\
350 \mathrm{~km} \text { from the [state] capital city }\end{array}$ \\
\hline Tyrone & 12 & $\begin{array}{l}8 \text { ha cattle property, } 20 \mathrm{~km} \text { from nearest } \\
\text { town, } 70 \mathrm{~km} \text { from regional centre, } \\
270 \mathrm{~km} \text { from capital city }\end{array}$ \\
\hline Will & 12 & $\begin{array}{l}420 \mathrm{ha} \text { property, } 60 \mathrm{~km} \text { from nearest } \\
\text { town, } 160 \mathrm{~km} \text { from regional centre, } \\
600 \mathrm{~km} \text { from capital city }\end{array}$ \\
\hline Luke & 14 & $\begin{array}{l}\text { Small, isolated property } 52 \mathrm{~km} \text { from } \\
\text { regional centre, } 250 \mathrm{~km} \text { from capital } \\
\text { city }\end{array}$ \\
\hline
\end{tabular}

*All locations and participant names have been changed to protect anonymity. 